\title{
Is Undiluted Goat's Milk Part of your Differential Diagnosis for Neonatal Metabolic Acidosis?
}

\author{
Nawar Dakhallah $^{1^{*}}$, Geneviève Maurice ${ }^{1}$, Geneviève Tremblay ${ }^{2}$, Christian Lachance $^{1}$ and Geneviève Benoit $^{1}$ \\ ${ }^{1}$ Division of Nephrology, Department of Pediatrics, CHU Sainte- Justine, Université de Montréal, Canada \\ ${ }^{2}$ Department of Pediatrics, $\mathrm{CHU}$ de Québec, Université Laval, Canada
}

"Corresponding author: Dr. Dakhallah N, MD, Division of Nephrology, Department of Pediatrics, CHU Sainte- Justine, Université de Montréal, Montreal, QC, H3T 1C5, Canada, Tel: 514 9526317; E-mail: nawar.dakhallah@umontreal.ca; nawar.dakhallah@gmail.com

Received date: November 14, 2016; Accepted date: November 22, 2016; Published date: November 28, 2016

Copyright: ( $) 2016$ Dakhallah N, et al. This is an open-access article distributed under the terms of the Creative Commons Attribution License, which permits unrestricted use, distribution, and reproduction in any medium, provided the original author and source are credited.

\begin{abstract}
Background: The differential diagnosis of neonatal metabolic acidosis is broad, including, among other things, lactic acidosis, inborn errors of metabolism and renal failure, in addition to diarrhea and renal tubular acidosis. The type of milk given to the newborn is less frequently evoked as a potential cause.

Case-diagnosis: We report the case of a 6-day-old baby with severe metabolic acidosis secondary to undiluted goat's milk. We will review other reported cases and analyse the composition of goat's milk.

Conclusion: When fed with undiluted goat's milk, neonates, with their immature acid-base regulation capacities, can develop metabolic acidosis secondary to an increased protein load and chloride content. Undiluted goat's milk should be considered in the differential diagnosis of neonatal metabolic acidosis.
\end{abstract}

Keywords: Neonates; Goat's milk; Metabolic acidosis; Normal anion gap

\section{Introduction}

Some parents choose undiluted goat's milk to feed their infants because of personal beliefs. This milk has been shown to be associated with adverse effects and is unsuitable, if not modified, to infants. In children, metabolic acidosis with a normal anion gap can be caused by à loss of HCO3-, most often due to diarrhea or, less commonly, secondary to type 2 (proximal) tubular acidosis. Other causes include type 1 (distal) renal tubular acidosis or type 4 RTA (hypoaldosteronism), leading to impaired $\mathrm{H}+$ excretion due to deficient renal acidification. In acidosis with elevated anion gap, an increase in unmeasured anions, along with hydrogen ion generation, is present; clinical settings include lactic acidosis, ketoacidosis, renal failure, inborn errors of metabolism and ingestion of drugs/toxins. Unmodified goat's milk is not often evoked as part of the differential diagnosis of metabolic acidosis in children.

\section{Case Report}

A Caucasian six-day-old boy with respiratory distress was brought to the emergency department of a primary care hospital in a rural area. The pregnancy was uneventful and the term-baby was born at home without any complications. The history was negative for consanguinity. The baby was drinking slightly less for the last day but there was no history of vomiting or diarrhea. On physical examination, the infant was afebrile, but drowsy. While he was tachypneic, his other vital signs were normal and his peripheral perfusion was adequate. He weighed $3300 \mathrm{~g}$ (birth weight: $3460 \mathrm{~g}$ ).

The first capillary blood gas done at the emergency department showed a $\mathrm{pH}$ of 7,21 with a $\mathrm{PCO}_{2}$ of $22 \mathrm{mmHg}$ and a $\mathrm{HCO} 3$ of 8.5
mmol/L. The electrolytes were as follows: $\mathrm{Na} 135 \mathrm{mmol} / \mathrm{L}$ (139-146), K $5.2 \mathrm{mmol} / \mathrm{L}$ (4-6.5) and $\mathrm{Cl} 116 \mathrm{mmol} / \mathrm{L}$ (98-113). The BUN level was $12.6 \mathrm{mmol} / \mathrm{L}$ (1-6.9) with a creatinine of $0.53 \mathrm{mg} / \mathrm{dL}(0.20-0.40)$. Calcemia and phosphatemia were normal, with a slight hypermagnesemia at $1.14 \mathrm{mmol} / \mathrm{L}(0.7-0.95)$. The complete blood count, liver function tests and albumin level were also in the normal range. Blood glucose was normal at $4.4 \mathrm{mmol} / \mathrm{L}$ and the dosage of lactic acid was $2 \mathrm{mmol} / \mathrm{L}(0.50-3.20)$. The urine analysis performed at the same time showed a $\mathrm{pH}$ of 5 , without glycosuria, proteinuria, hematuria or leucocyturia.

Hydration through a peripheral IV access was started. After performing blood, urine and cerebrospinal fluid cultures, in addition to a chest X-Ray, antibiotics were started. The patient was transferred the same day to a tertiary care pediatric hospital and admitted in the neonatal care department. These tests did not reveal, afterwards, infection.

The repeated capillary blood gas confirmed a pH of 7.19, PCO2 of $25.0 \mathrm{mmHg}$ and $\mathrm{HCO}_{3}$ of $9.0 \mathrm{mmol} / \mathrm{L}$ with similar electrolytes. In order to rule out a metabolic disorder or a renal tubular acidosis, consultations in genetics and nephrology were performed. Blood levels of glucose, ammoniac, lactate and pyruvate were normal. A proteinfree formula was initially suggested, while the rest of the metabolic work-up was pending. The results of plasmatic amino acids chromatography in addition to urine amino acids and organic acids came back as normal. Urine electrolytes, performed after one dose of intravenous bicarbonate $(1 \mathrm{mEq} / \mathrm{kg})$, but while the patient still had metabolic acidosis, were: $\mathrm{Na} 48 \mathrm{mmo} / \mathrm{L}, \mathrm{K} 25 \mathrm{mmol} / \mathrm{L}$ and $\mathrm{Cl} 79$ $\mathrm{mmol} / \mathrm{L}$ (slightly negative urinary anion gap). A renal ultrasound showed no signs of nephrocalcinosis.

Based on these results, a metabolic acidosis due to goat's milk consumption started to be the most probable diagnosis. Indeed, the 
baby was fed exclusively unmodified goat's milk from 36 hours after birth because of his parent's personal beliefs and suspected cow milk protein allergy in the family.

The patient received only two other similar doses of bicarbonates and intravenous fluids were gradually ceased. Feeding with a hypoallergenic formula was re-introduced and the patient's blood gas went rapidly back to normal 36 hours after admission with resolution of tachypnea.

\section{Discussion}

We describe the case of a 6-day-old boy who presented a metabolic acidosis with a normal anion gap caused by the consumption of undiluted goat's milk. The baby's respiratory distress seemed to be the result of a Kussmaul breathing phenomenon in response to metabolic acidosis. After excluding acidosis secondary to hypoperfusion and infection, a metabolic and renal work-up were initially requested in order to determine the cause of this acid-base disorder.

In 1979, Harrison et al. addressed the case of a 3-week-old infant fed with undiluted goat's milk who presented with tachypnea and growth failure. Metabolic acidosis was severe with a $\mathrm{pH}$ at 7.14, $\mathrm{HCO}$ at 4 $\mathrm{mmol} / \mathrm{L}$ and an anion gap of 11 [1]. The infant improved following hydration, administration of sodium bicarbonate and switching for a standard formula. When undiluted goat's milk was given back, the infant lost weight and redeveloped a metabolic acidosis. Another case reported a 7-day-old girl nourished with undiluted goat's milk since birth who presented a metabolic acidosis with an anion gap of 10 associated with hyperkalemia, hypophosphatemia and elevated blood urea. A renal tubular acidosis was initially part of their differential diagnosis [2]. In addition, a 5-month-old boy fed with raw goat's milk since the age of approximately 4 months developed intracranial infarctions in the setting of severe hypernatremia and azotemia; the patient had increased anion gap metabolic acidosis [3]. Finally, two cases of undiluted goat's milk consumption mimicking metabolic diseases have been reported. Tyrosinemia type 1 was initially suspected in a 6-day-old infant, who was fed with undiluted goat's milk since day two of life. The result of tyrosinemia screening method was abnormal but this disorder was finally excluded [4]. Another falsely positive newborn screening, compatible with maple syrup urine disease, was reported in a 12-day-old girl nourished with undiluted goat's milk since birth [5].

Goat's milk contains between $3.56 \mathrm{~g}$ of protein and $50 \mathrm{mg}$ of sodium per $100 \mathrm{~mL}(22 \mathrm{mmol} / \mathrm{L})$, which is approximately three times that of human milk (1.03 g and $17 \mathrm{mg}$ per $100 \mathrm{~mL}$ ) [3]. There is also $242 \mathrm{mg}$ of potassium $(62 \mathrm{mmol} / \mathrm{L})$ and $202 \mathrm{mg}$ of chloride $(57 \mathrm{mmol} / \mathrm{L})$ per $100 \mathrm{~mL}$ [1]. A standard milk-based formula contains per $100 \mathrm{~mL}, 1.5 \mathrm{~g}$ of protein, $25 \mathrm{mg}$ of sodium $(11 \mathrm{mmol} / \mathrm{L}), 74 \mathrm{mg}$ of potassium $(19$ $\mathrm{mmol} / \mathrm{L})$ and $43 \mathrm{mg}$ of chloride $(12 \mathrm{mmol} / \mathrm{L})$ [1]. High quantity of protein generates a higher protein catabolism, which produces net acid like sulphates and phosphates. Moreover, a higher potassium and especially chloride content may also contribute to acidosis by decreasing, respectively, the ammoniagenesis and bicarbonate concentration [2].

Age and renal maturity definitely play an important role in the development of undiluted goat's milk acidosis. The newborns have a reduced ability to respond to an acid load. Bicarbonate reabsorption in the proximal tubule is about one third that of the adult [6] and ammoniagenesis occurs at a much lower rate $[7,8]$. In addition, microperfusion studies of neonatal rabbit kidneys demonstrate a low capacity to secrete acid compared with their adult controls [9]. In the case presented here, the siblings also consumed goat's milk without clinically evident side effects. Other cases reported siblings (of an index case with metabolic acidosis secondary to goat's milk) fed with this same milk since birth or the age of 6 months without clinical complications, although mild metabolic disturbances could not be excluded as no blood tests were performed. This variability of tolerance to the acid load of goat's milk is not explained.

Finally, in addition to severe electrolyte abnormalities and metabolic acidosis, unmodified goat's milk has also been associated with megaloblastic anemia, allergic reactions including life-threatening anaphylactic shock, hemolytic uremic syndrome, and infection [10-13].

\section{Conclusion}

Undiluted goat's milk consumption should be included in the differential diagnosis of unexplained neonatal metabolic acidosis. Newborns are more vulnerable to develop acidosis because of their immature renal physiology. High protein content in this milk generates a high acid load that exceeds neonatal acid-base regulation capacities. Parents should be informed about possible severe consequences of feeding their child with undiluted goat's milk.

\section{References}

1. Harrison HL, Linshaw MA, Bergen JS, McGreeny T (1979) Goat milk acidosis. J Pediatr 94: 927-929.

2. Jorquera P, Wu J, Bockenhauer D (1999) Nonanion gap metabolic acidosis in a newborn. Curr Opin Pediatr 11: 169-173.

3. Basnet S, Schneider M, Gazit A, Mander G, Doctor A (2009) Fresh goat's milk for infants: myths and realities - A review. J Pediatr 125: 973-977.

4. Hendriksz CJ, Walter JH (2004) Feeding infants with undiluted goat's milk can mimic tyrosinaemia type 1. Acta Paediatr 93: 552-553

5. Chapman KA, Ganesh J, Ficicioglu C (2008) A false-positive newborn screening result: goat's milk acidopathy. Pediatrics 122: 210-211.

6. Schwartz GJ, Evan AP (1983) Development of solute transport in rabbit proximal tubule. I. HCO-3 and glucose absorption. Am J Physiol 245: F382-390.

7. Goldstein L (1970) Renal ammonia and acid excretion in infant rats. Am J Physiol 218: 1394-1398.

8. Goldstein L (1971) Ammonia metabolism in kidneys of suckling rats. Am J Physiol 220: 213-217.

9. Mehrgut FM, Satlin LM, Swartz GJ (1990) Maturation of HCO3transport in rabbit collecting duct. Am J Physiol 259: F801-808.

10. Harrison ME, Hilliard RI (2007) You look like you've seen a goat. Paediatr Child Health 12: 389-391.

11. Pessler F, Nejat M (2004) Anaphylactic reaction to goat's milk in a cow's milk-allergic infant. Pediatr Allergy Immunol 15: 183-185.

12. Bielaszewska M, Janda J, Blahova K, Minarikova H, Jikova E, et al. (1997) Human Escherichia coli O157:H7 infection associated with the consumption of unpasteurized goat's milk. Epidemiol Infect 119: 299-305.

13. Sacks JJ, Roberto RR, Brooks NF (1982) Toxoplasmosis infection associated with raw goat's milk. JAMA 248: 1728-1732. 